\title{
GPSとNTPを用いた船内コンピュータの時刻整合法
}

\author{
冨永 敏明*・添田 忍 ${ }^{* *} \cdot$ 鈴木 治***安田 明生*
}

\section{Time Adjustment Method for Onboard Computer with GPS and NTP}

\section{Toshiaki TOMINAGA, Shinobu SOEDA, Osamu SUZUKI and Akio YASUDA}

\begin{abstract}
It is important to synchronize the real time clock with standard time in computer network. The clock of the computer on land can be adjusted through the Internet to the time server for reliable network.

Shipboard LAN or Internet via IMMARSAT is set up quickly onboard. But, some troubles are found in the file maintenance and e-mail exchange onboard, because the clock can not be adjusted to the standard time. It is impossible to connect the clock of the shipboard computer to Internet from the ship on the ocean.

Thus, the authors propose the time adjustment method is for onboard computer with NTP (Network time protocol) and GPS receiver. We improve the 'daytime' protocol to be reinforced with the basis local time and difference from UTC. Then we acquired the data by our system on land and ocean. The results are as follows.

1) Time synchronous GPS receiver is best time source among GPS, public NTP through PHS, and Radio clock with low frequency. The accuracy for setting NTP sever is $10 \mathrm{~ms}$ and it is $50 \mathrm{~ms}$ for ocean going vessel.

2) NTP server supported by GPS serves to offer the time standard instead of the UTC time signal by short wave broadcasting.

3) OS of MS Windows XP can set local time information (LTI) with the aid of the enhanced daytime protocol via shipboard LAN.

4) Radio clock by low frequency (JJY - $40 \mathrm{kHz}$ ) is good time source and the synchronous precision for NTP sever is $14 \mathrm{~ms}$. But it is not useful for ocean going ships, as the service area is limited to around Japanese archipelago.

5) The proposed time adjustment method with the precision of $50 \mathrm{~ms}$ is useful for time adjustment onboard.

Keywords: GPS, Shipboard LAN, Network Time Protocol, Daytime Protocol, Marine Clock

キーワード : GPS、船内 LAN、ネットワークタイムプロトコル、デイタイムプロトコル, 船内時計
\end{abstract}

\section{1. はじめに}

船上での時刻管理は、主として船内時計の世界時 に対する同期維持と、地方時設定とによってなされ てきたが、近年の急速なネットワーク化により、船 内の Personal Computer(以下 PC)についても同様な時
刻管理が必要となっている。筆者らは、船上におけ る PC 時刻管理の問題点として、基準時刻となる時 計から PCへの時刻供給ができないこと、インター ネット接続による時刻整合ができないこと、そして PC 自体に船内時を設定する機能がないことに注目

\footnotetext{
* 正会員 東京海洋大学海洋工学部（广135-8533 東京都江東区越中島 2-1-6）

** 正会員 航海訓練所（广231-8435 神奈川県横浜市中区北仲通 5-57)

*** 正会員 鳥羽商船高等専門学校（T517-8501 三重県鳥羽市池上町 1-1）
} 
し、GPS と $\operatorname{NTP}^{(1)}($ Network time protocol)を用いた時 刻整合法を提案し、陸上及び船上で時刻同期精度計 測及び作製したプログラムの検証実験を行った。

なお、本論文では時刻差が生じないよう調整する 作業を「同期」、時刻差を修正する作業を「整合」と 定義する。

\section{1 治泊での時刻管理手法}

現在、船舶では船舶用水晶時計(Fig.1)を船内の基 準時計として採用することが多い。船上での時刻管 理業務には、航海士が海域毎に受信可能な各国の報 時放送 ${ }^{(2)}$ を受信して船舶用水晶時計の親時計を協定 世界時 (以下 UTC)に同期させる作業と、モニタ一子 時計の時刻設定を行う地方時管理作業がある。

地方時(Local Time)には入港国の地方標準時だけ でなく、航海中の正午位置によって算出される船内 時(3)があり、必要に応じて UTC との時差を変更する 時刻改正が実施される。時刻改正時には、船舶用水 晶時計の操作により、親時計から同期信号が発せら れ、地方時表示用に船内各所に設置された子時計と データロガーの時刻を一斉に更新できる(4)。乗組員 の個人用時計などは最寄りの子時計を見て各自が船 内時へ整合させている。

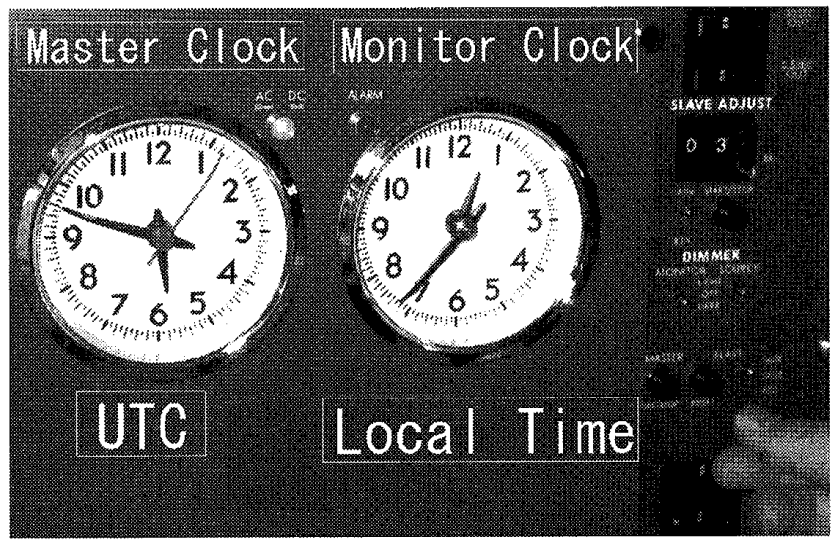

Fig.1 Marine master clock

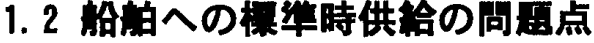

日本標準時(以下 JST)は、情報通信研究機構から JJY というコールサインを持つ標準電波によって供 給されてきたが、2001 年 3 月末以降、短波による報 時放送を取り止め、長波での時刻コード放送のみを 行うようになった。

時刻コード放送は電波時計など多様な機器で自動 的な時刻同期が可能であるが、従来の短波報時放送 と違い、受信電波を耳で聞くだけでは時刻が分から ないこと、また、利用可能範囲が福島および福岡県 の 2 箇所の送信所加半径 $1200 \mathrm{~km}$ の日本周辺に限
定されたことから、洋上を航行中の船舶での利用が 困難な状況となった。

\section{1. $3 \mathrm{PC}$ 時刻管理の问筑点}

船上での PC 時刻設定は船舶用水晶時計の子時計 を見て手動で行っているが、MS Windows 系の OS では、船内時のような任意の時刻帯を設定できない。

使用者も PC 内部時計の整合についてそれほど注 意を払っておらず、船内 LAN 上の共有ファイルや 電子メールでのトラブルが生じている(5)。

また、Windows XP の規定值では PC 起動時、自動 的にインターネット上の時刻サーバへ接続し、PC 内部時計を整合させるようになっているが、船上で のインターネット接続は困難(6)である。

\section{4 本研究の目的}

情報通信研究機構が行った原子時計を時刻源とす る NTP 実験*で NTP クライアントは、LAN 上で UNIX 系 OS に対して $0.95 \mathrm{~ms}$ 、Windows 系 OSにつ いては約 $50 \mathrm{~ms}$ の標準偏差で時刻同期させることが できると報告されている(7)。

本研究は、PC を短波報時放送に替わる船上での標 準時供給源として位置づけ、船内 LANにおいて NTP を用いて陸上と同等の性能で時刻同期させる手法に ついて検討した。

さらに、船上での PC 使用の利便性を高め、ネッ トワーク内のトラブル防止を図るため、船内時への 対応も含めた PC 時刻自動整合手法の確立を目指し た。

\section{NTP と航法用 GPS による時刻供辁}

NTP は、UNIX 系 OS 上で、ネットワーク内にあ るコンピュータ間の時刻同期を目的として開発され たフリーソフトウエアで、サーバプログラムである ntpd や、サーバの同期状態を示す ntpq、クライアン トとして時刻を整合する ntpdate などが公開されて いる。

これらを NTP サーバとして使用する場合には、原 子時計などを時刻源として設定でき、時刻源から得 た UTC に同期して自らのネットワークへ時刻を供 給する仕組みを有している。時刻の分解能は実装上 $10^{-12}$ 秒である。

一方、これらを NTP クライアントとして使用する 場合には、NTPサーバとの接続時間差をもとにネッ トワーク伝送経路による遅延量を計算し、UTC 情報 を調整したうえでコンピュータ内部時計を同期させ

\footnotetext{
${ }^{*}$ Experimental NTP Server,http://www.jst.mfeed.ad.jp
} 
る機能がある。

さらに伝送経路による遅延量が過大な NTP サー バとの同期を防ぐ仕組みや、複数の NTP サーバの中 から最も正確なものを選択する機能をも持つ。

\section{1 杭法用 GPS からの UTC 供給}

GPS 受信機は、測位のみならず、正確な UTC を 算出することができる。航法用 GPS 受信機は、自船 位置や針路、速力などの航法情報を表示するだけで なく、得られたデー夕を他の航海計器に供給するた め RC-232C やカレントループ方式の出力ポートが 用意されている。一般的に船舶では電圧の変化で情 報を伝送する RS-232C ポートよりも、電流の変化で デジタル情報を伝送するカレントループポートがノ イズに強いため多く用いられていて、データの出力 形式は NMEA 形式(National Marine Electronics Association 0813 Standard)に統一されている。

UTC 日付時刻情報は NMEA 形式のデータのうち \$GPRMC センテンスのデータとして、1 秒ごとに出 カされているので、これを船上での時刻源として利 用することができる。

\section{$2.2 \mathrm{PC}$ 遇延至と NTP を用いた時刻䍀合}

Fig.2 は陸上のインターネット接続環境において、 日本標準時を供給する情報通信研究機構が運営する NTP サーバ(一般向けには MFEED が供給)を時刻源 として NTP Ver.4.2.0の ntpdate コマンドを用いて 1 日 1 回、PC を整合した場合の修正量を示す。PC毎 に一定の修正量があり、PCA では 1 日に 8 秒、PC B と PCD は 3 秒、最も少ない PC C でも 0.5 秒の修正 が必要で、PC 内部時計の遅延量の大きさと、NTP による時刻整合の必要性が分かる。

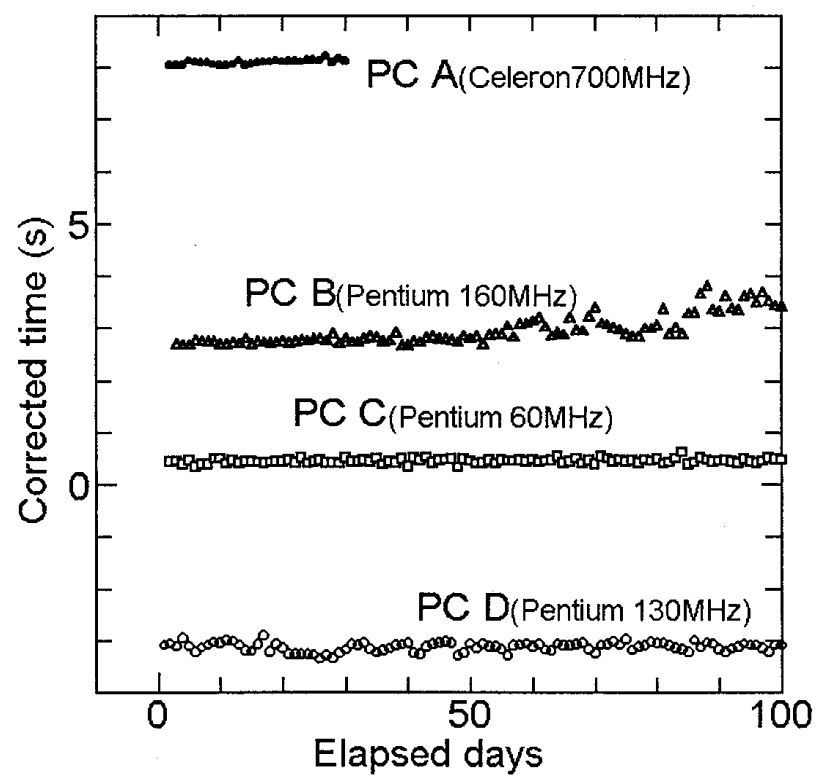

Fig.2 Daily time correction by NTP for various PCs
Fig.3 は神戸港に停泊中の航海訓練所練習船「北斗 丸」において PC 内部時計を基準として、電波時計 から供給された時刻と、PHS 回線を使ったインター ネットへの常時接続によって公共 NTP サーバから 得た標準時刻との時刻差を表した図である。いずれ の時刻差も 12 時間後には約 1 秒に達しており、長時 間 PC 内部時計の整合をせずに放置した場合一定の 遅延量を生じていく様子を表している。

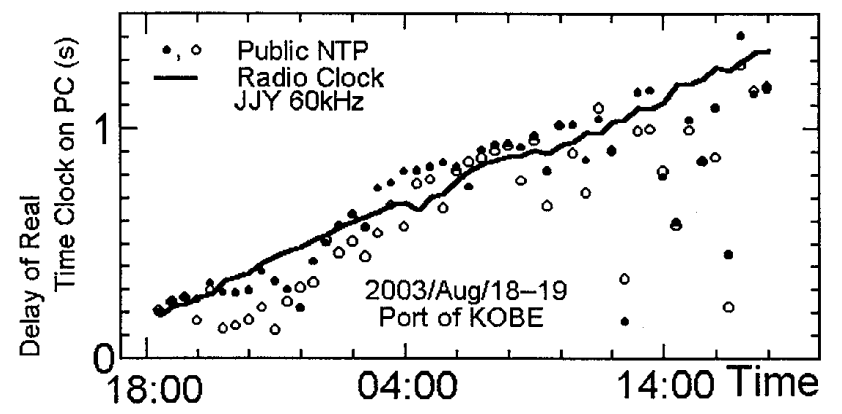

Fig. 3 Time offset of NTP Servers

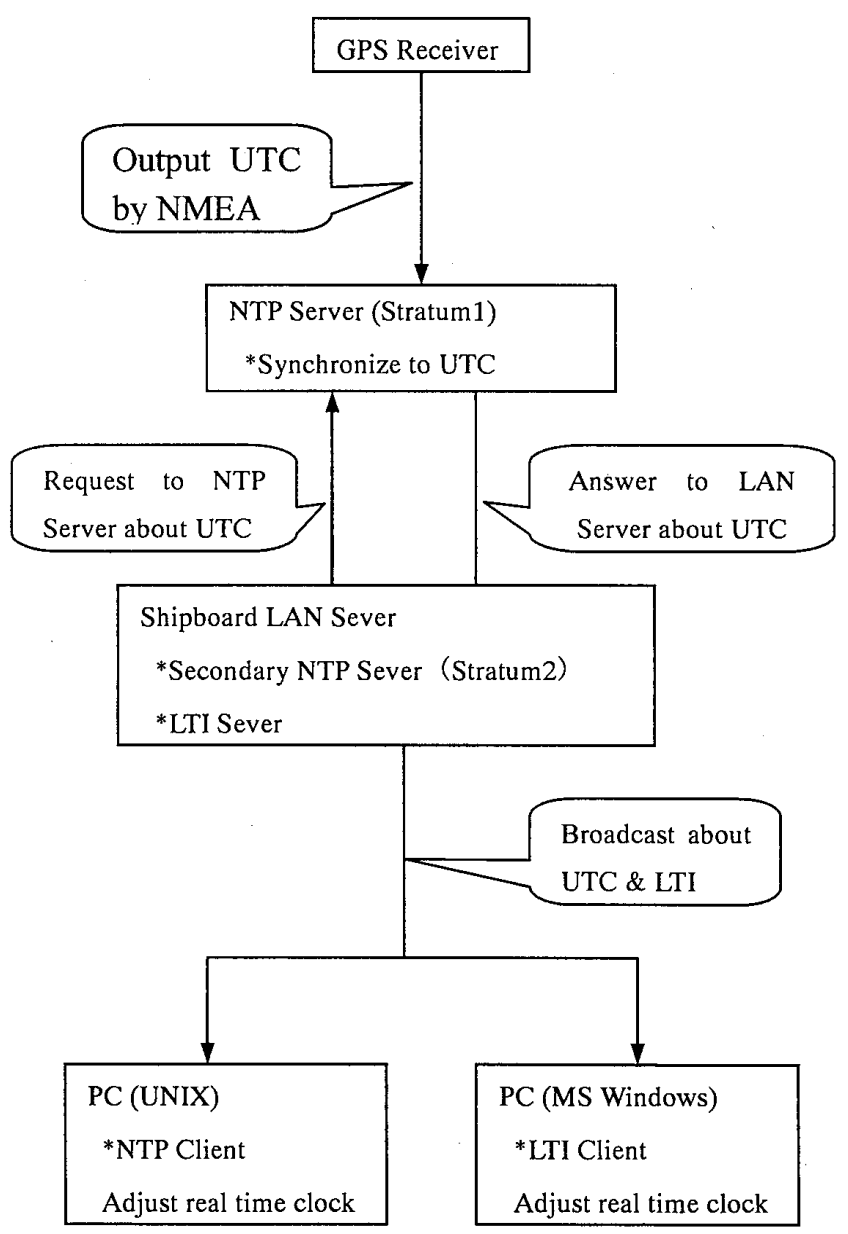

Fig.4 Diagram of NTP and LTI server system for Shipboard LAN

\section{3 治内時に対底する地方時情報の供蛤}

船上では NTP を用いた UTC 同期に加え、各 PC 
の使用時刻帯を船内時に設定する操作が必要となる。 この操作を自動的に行うため、Daytime プロトコ ル (8)を拡張し、使用地方時情報と UTC との時差情報 を地方時情報(Local Time Information 以下LTI)として、 LTIサーバから供給することとした。

\subsection{GPS とNTP を用いた時刻整合法}

Fig.4 は GPS とNTP を用いた時刻整合法のシステ ム構成図である。NTPサーバは GPS 受信機を時刻源 として UTC との同期を行い、船内 LAN サーバへ UTC を供給する。NTP サーバに時刻同期した船内 LAN サーバは UTC と LTI をネットワークに配信す る。各 PCでは UNIX 系 OSについてはNTP クライ アントが、MS Windows 系 OS についてはLTI クライ アントプログラムが内部時計を船内時へ整合させる ことになる。

\section{3. 陸上実确}

通常、NTPサーバには時刻同期用 GPS 受信機が使 用されているが、Fig.4の仕組みの沉用性を高めるに は、船舶で利用している航法用 GPS 受信機を時刻源 としなければならない。そこで航法用 GPS 受信機が 正確に標準時を供給できるかを確認するため、鳥羽 商船高専において手持ちの GPS 受信機を利用して 標準時との比較を行った。

比較対象として、JSTを提供し精度が評価されて いる MFEED との接続によって JST に時刻同期した NTPクライアントを用いた。また、GPS 受信機のア ンテナは 4 階屋上に設置し、カレントループ方式の 出力についてはコンバー夕(ラインアイ社製： SI-10FA)を付加して RS-232C 形式に変換して計測を 行った。

\section{1 出力形式と虺延量}

Table 1 は、航法用 GPS による NTP サーバと、JST と同期した NTP サーバとの遅延を示したものであ る。

Table 1 Constant delay of GPS output type

\begin{tabular}{|l|c|}
\hline Model (Type of Transfer) & Constant Delay \\
\hline FURUNO GP-80(Current Loop) & $380 \mathrm{~ms}$ \\
\hline FURUNO GP-36(RS-232C) & $737 \mathrm{~ms}$ \\
\hline FURUNO GP-36(Current Loop) & $951 \mathrm{~ms}$ \\
\hline JRC JLR-5500(RS-232C) & $3043 \mathrm{~ms}$ \\
\hline
\end{tabular}

プレジャーボート用 DGPS 受信機 GP-36 の RS-23 $2 \mathrm{C}$ 方式とカレントループ方式では、後者の方が $200 \mathrm{~ms}$ ほど遅く、大型船用の GP-80 ではカレントル ープにもかかわらず、遅延は380ms であった。

今回、同一機種を複数個持ち合わせていなかった ため、これら遅延量が、機器特有の值であるのか、 個体による差なのかは判断できないが、事前に遅延 量を計測しオフセットを設定することで、航法用 GPS 受信機でも NTPサーバが構築できる。

また、航法用 GPS から各種計器にUTC を含む航 法情報が供給されているが、遅延量が含まれている ことを認識した上で運用しなければならないことが 分加っ。

なお、時刻同期用 GPS ではオフセットが予め決定 されているので設定は不要である。

\section{2 時刻洦こととの远蝴時刻同期}

Fig.5は、GP-36 と 40kHz の長波報時放送を受信し て每分同期を試みる電波時計(Tristate 製)を時刻源と する NTP サーバ及び 2 つの公共 NTP サーバと MFEED に同期させたNTPサーバのとの時刻のずれ (Time offset)を ntpdate コマンドによって 5 分ごとに 計測したものである。

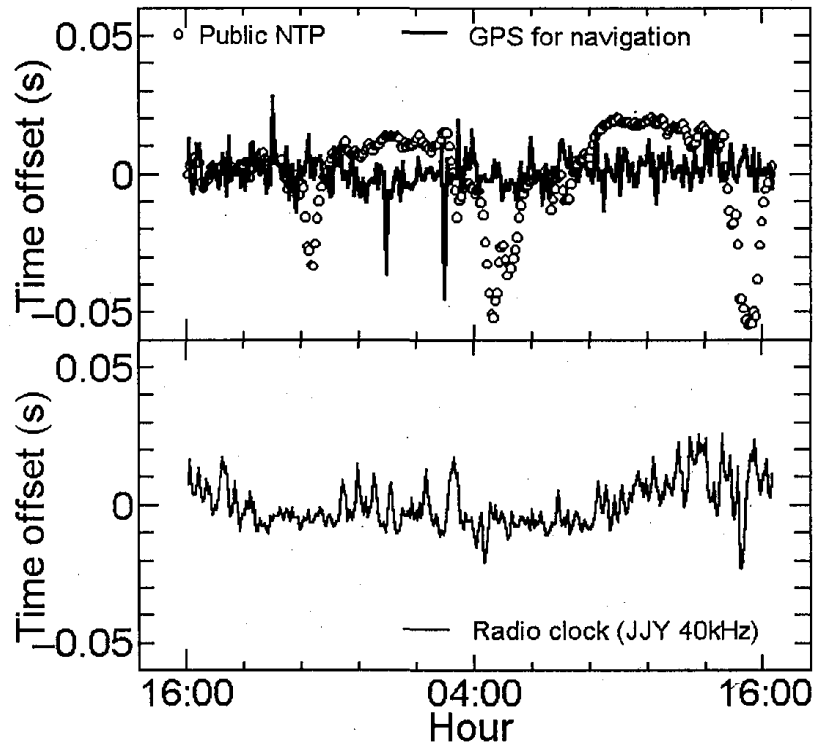

Fig.5 Time offset of various NTP Servers

GPSによる時刻は安定した時刻差であるのに対し て、公共 NTP にはばらつきが見られる。なお、電波 時計の受信には屋外に設置したプリアンプ内蔵の長 波専用アンテナ（RF Systems 社製 LF-150）を利用し たが、外来雑音のため受信不能になり、時々同期が 外れることが分かった。

Table 2 は同様の方法で各種 GPS 受信機及び電波 時計を時刻源とするそれぞれ NTP サーバそれぞれ の Time offset 24 時間計測した時の標準偏差を示 したものである。 
時刻同期用 GPS(Garmin 製 eT36tm)では、Time offset の標準偏差は $0.8 \mathrm{~ms}$ であり、UTC と同期して 出力されている PPS(Pulse Per Second)信号の公称精 度は土 $1 \mu \mathrm{s}$ であるが，この NTP の時刻比較精度は $1 \mathrm{~ms}$ であった。

Table 2 Standard deviation of Time offset various

Time sources

\begin{tabular}{|l|ll|c|}
\hline Time source & model & St. Dev. \\
\hline DGPS for Ocean Going ship & FURUNO GP-80 & $53 \mathrm{~ms}$ \\
\hline DGPS for Pleasure Boat & FURUNO GP-36 & $8 \mathrm{~ms}$ \\
\hline Portable GPS & JRC JL-5500 & $402 \mathrm{~ms}$ \\
\hline DGPS for Time Syncro & Garmin eT36tm & $1 \mathrm{~ms}$ \\
\hline Radio Clock & Tristate (JJY-40kHz) & $14 \mathrm{~ms}$ \\
\hline Public NTP Sever & ntp2.jst.mfeed.ad.jp & $17 \mathrm{~ms}$ \\
\hline
\end{tabular}

一方、航法用 GPS においても、大型船用及びプレ ジャーボート用では、標準偏差がそれぞれ、 $50 \mathrm{~ms}$ 程度と $8 \mathrm{~ms}$ であり、目標值に達している。

携帯型 GPS では 400ms と目標値に達してはいない ものの、自動的に時刻整合が行えるという意味では、 一考の余地はあると思われる。電波時計についても 標準偏差 $14 \mathrm{~ms}$ であり、目標值以内であった。

\section{4. 船上实的莫}

実船実験に使用した船舶の要目及び実験海域を Table 3 に示す。

Table 3 Principal dimension of onboard experiment

\begin{tabular}{|l|c|c|}
\hline & T.S. Hokuto Maru & T.S. Kaiwo Maru \\
\hline Type & SteamTurbineVessel & Sailing Vessel \\
\hline LOA & $124.80 \mathrm{~m}$ & $110.09 \mathrm{~m}$ \\
\hline Gross ton & $5877.19 \mathrm{t}$ & $2556 \mathrm{t}$ \\
\hline Exp. Area & Japan & Pacific Ocean. \\
\hline OS & FreeBSD 4.3 & FreeBSD 5.0 \\
\hline NTP & NTP Ver.4.2.0 & NTP Ver.4.1.0 \\
\hline
\end{tabular}

\section{1 時刻源ことの NTP サーバ時刻同期福度}

航法用 GPS の GP-36 と電波時計を時刻源とする NTPサーバそれぞれの時刻を比較する実験を「北斗 丸」船上で行った。なお、GP-36 のアンテナとして GPS アンテナ内蔵の磁界型 DGPS アンテナを羅針儀

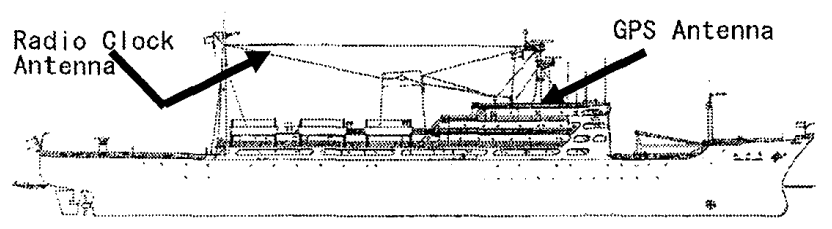

Fig.6 Antenna Location on Hokuto Maru
甲板に設置した。また、電波時計には北斗丸既設の 逆 $\mathrm{L}$ 型アンテナ( $92 \mathrm{~m}$ 長)に専用のアンテナカップラ を介して受信回路に接続することとした(Fig.6.)。

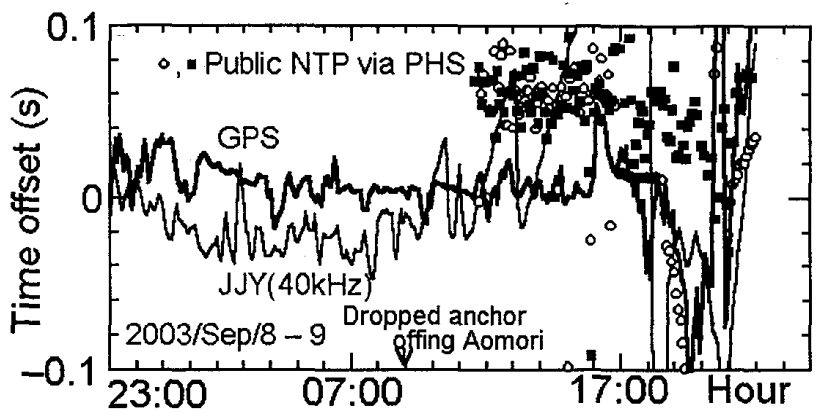

Fig.7 Time offset about NTP Server with various time sources

Fig.7 は青森錨泊前後における時刻源ごとの時刻 同期精度計測結果を示す。錨泊後にはPHS 回線が使 用できたため、2つの公共 NTP サーバに接続した結 果も併せて示している。

青森錨泊前、航行時の GPS と電波時計の時刻差の 標準偏差は $14 \mathrm{~ms}$ と $11 \mathrm{~ms}$ であり、陸上実験とは数 $\mathrm{ms}$ の差が生じているが、いずれも目標值以内であり、 航法用 GPS と電波時計による NTP サーバは航行中 の船舶においても有効であることが分かった。

なお、錨泊後の PHS 回線接続による公共 NTP サ 一バでは時刻差の標準偏差が $242 \mathrm{~ms}$ 及び $112 \mathrm{~ms}$ と航 法用 GPS と電波時計に比べ 10 倍近く大きく、PC 時 刻同期精度 $50 \mathrm{~ms}$ の目標值に達しないことが確認さ れた。

また、電波時計では錨泊後、同期精度が著しく低 下しているが、これは、外来ノイズによって受信不 能となり、NTP サーバが同期を外されたことが原因 である。

\section{2 NTP による時刻估報の船内利用}

航海訓練所練習帆船「海王丸」において、船内 LAN を用いた時刻同期実験を行った。今回は時刻同期精 度を更に向上させるため、時刻同期用 GPS 受信機

（Garmin 製 MARS15HTMt、PPS 公称精度 $\pm 1 \mu \mathrm{s}$ ) を利用した NTP サーバ（Fig.4の Stratum1に相当） を設け、船内 LAN を構成する既設ファイルサーバ と船陸間通信用サーバの 2 台（Stratum2 に相当）に NTPサーバをインストールし Stratum1 と 2 にる階 層構造を導入して日本とニュージーランドを往復す る訓練航海中、長期にわたって時刻整合法を利用す る実験を行った。

それぞれのサーバ間の時刻差は、時刻同期用 GPS を用いた NTP サーバでは、1 $\mathrm{ms}$ 以下の時刻差しか生 じず安定していたが、ファイルサーバと船陸間通信 用サーバについては $2 \mathrm{~ms}$ の変動が見られた。このこ 
とから、NTP サーバの時刻同期精度はコンピュータ やネットワークの負荷によって変動するため、船内 LAN サーバへ時刻源を直接接続せず、専用 NTP サ 一バを設けて階層構造を持たせれば、精度向上が可 能であろう。

\section{3 共有ファイルによるPCでの紿内時の表示}

海王丸では NTP により時刻整合した PC 上に船内 時、JST、UTC、UTC との時差、目的地の地方標準 時などの情報表示と、必要に応じて時分を wave フ アイルを用いてアナウンスするプログラムを作製し、 航海中、PC で利用する他、船内テレビアンテナ分配 ケーブルを経由した船内放映を行った。

Fig.8 はファイルサーバ内に共有ファイルとして 保存された UTC と LTI をもとに、時刻を表示するプ ログラムで、PCの時刻は変更せずに船内時を表示す る。Fig.8の画面の表示時刻を視覚で、日本以外の国 が行っている短波報時放送を聴覚で比較したところ 常時、時刻差を感じることがなく、GPS とNTPを利 用したコンピュータの時刻整合法を応用する仕組み が短波報時放送の代替手段となることが確認できた。

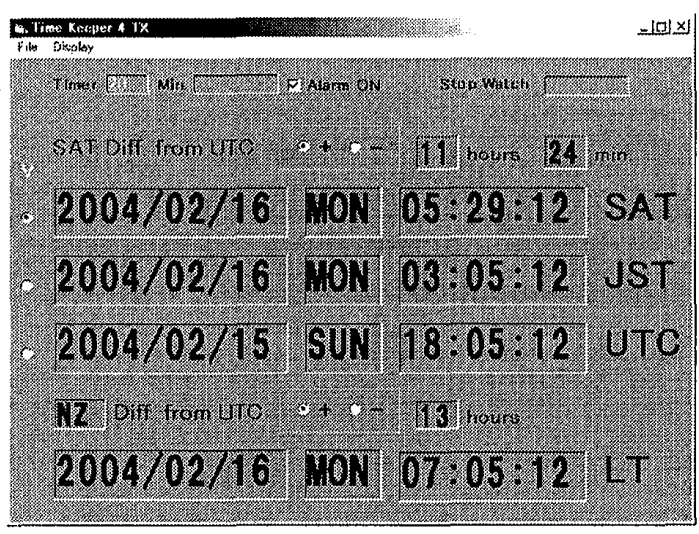

Fig. 8 Time Information Broadcast Program

\section{4 PPS による同期新度の梌正}

太平洋上を航行中の海王丸において、時刻同期用 GPS 受信機の PPS 信号出力を FreeBSD の PPS 同期 機能を使って、NTP 同期精度の検証実験を行った。 ここでは通常の NMEA 出力に同期させた NTP サ 一バと、NMEA 出力と PPS 信号出力との両者に同期 させた NTP サーバとの時刻差を測定した。ただし、 UTC との同期状況は計測の対象としていない。

NMEA 出力の夕の場合 $10 \mathrm{~ms}$ 程度の時刻差を生じ たが、PPS 信号を利用した NTPサーバではほとんど 変動が見られなかった。

\section{LTI サーパとクライアントの実装}

船内で利用者の多いMS Windows 系 OS の時刻設 定法では、レジストリに登録されていない時刻帯は、 全て UTC-12 時間の時刻帯と認識され、船内時の設 定ができない。

Visual Basic Ver.6.0の GetTimezoneInformation 関数 と SetTimezoneInformation 関数を用いたクライアン 卜用時刻整合プログラム(Fig.9)によって、PC 時刻整 合とレジストリへの時刻帯登録を同時に行い PCへ の船内時設定が可能となった。

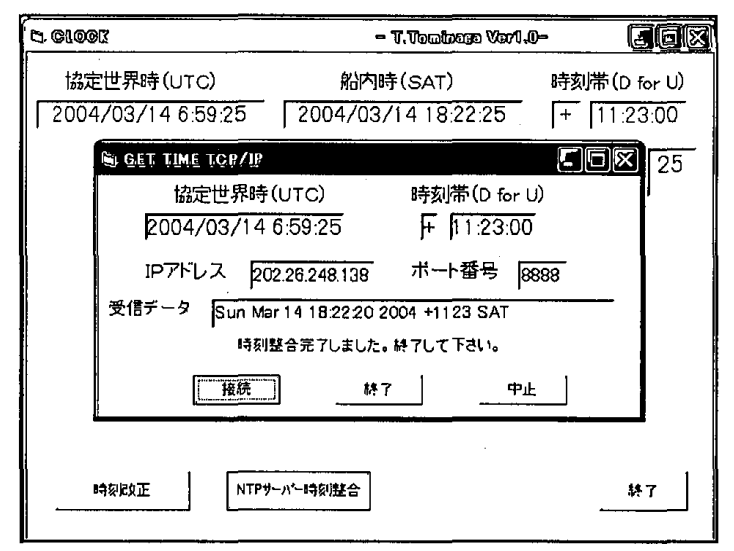

Fig.9 LTI client program for Windows XP

\section{6. まとめ}

本研究では、航法用 GPS と NTP を用いた時刻整 合法の陸上及び実船実験および試作ソフトウェアの 使用を通じて以下のことが確認された。

1) 船上で使用する NTP サーバの時刻源として、PPS 信号出力のある時刻同期用 GPS 受信機を用いれば 容易に無調整で UTCに同期でき、PPS を用いない場 合でも $10 \mathrm{~ms}$ 程度の同期精度が得られた。

2) 航法用 GPS をNTP サーバの時刻源とした場合、 受信機から NTP サーバまでのデータの伝送遅延を 計測する必要があるものの、 $50 \mathrm{~ms}$ 程度の同期精度が あり、日常利用に必要な精度を確保できる。

3) 試作した NTP サーバから時刻を取得、表示する ソフトウェアは、短波報時放送の代替手段とするこ とができた。

4) NTP サーバを階層構造にすると、クライアントか らの接続を最小限に抑えられ、同期精度が数 $\mathrm{ms}$ 向 上する。

5) 本研究で提案した Daytime プロトコルの拡張と、 レジストリの追加登録によって MS Windows 系 OS でも、標準では不可能な船内時の設定が可能となっ た。

6) 受信可能範囲が $1000 \mathrm{~km}$ 程度と狭いながら、電波 
時計の時刻同期精度は航行中の実験により、航法用 GPS 受信機と同程度の同期精度を持ち、船舶での利 用にも有効であった。

このように、既存の航法用 GPS や陸上用の電波 時計がNTPによって船内の PC 時刻を容易に同期で きることが明らかになった。ただし、これらの機器 を利用する場合は、UTC出力遅延量を、精度の高い 標準時供給源を持つ陸上で行うか、時刻同期用の GPS を利用して計測する必要がある。

時刻同期 GPS 受信機は航法用 GPSよりも廉価に なっているので、時刻同期用 GPS こ NTPサーバを 船内に設置することは実用性が高いといえる。

\section{辞}

実船実鈳にご協力くださいました航海訓練所練習 船「海王丸」「北斗丸」の皆様に深く感謝の意を表し ます。

\section{考文献}

(1) インターネット RFC 辞典 : アスキー社, pp.352-355

(2) 船舶通信士労働組合技術専門委員会編：

世界無線通信資料、pp.648-650,pp.703-706

無線通信社,2002 年

（3）長谷川健二：天文航法、pp.45-48,p.341、

海文堂、昭和 54 年 3 月 15 日

(4) 井関 貢 : 新訂航海計器学、p.163、海文堂

昭和 52 年 3 月 20 日

(5) 鈴木 治、Borje Fossell 安田明生：インターネッ 卜標準技術を使った船員のための陸船間の電子 メールシステムの提案、日本航海学会論文集, 第 104 号, pp.71-77 2001 年 3 月

(6) 鈴木 治 : 船陸間メールインターネット利用の将 来について,航海学会誌 Vol.158,pp.10-19、2003 年 12 月

（7）佐藤克久、浅利一善：NTP 時刻同期精度の OS 依存性について、融合科学研究所技術研究会報 告、pp.263-266, 2002 年.

(8) J.Postel : Daytime Protocol, RFC 867

\section{缶疑底答}

\section{笹尾 昭（古野龟気株式会社）:}

自動的に船内時計を整合させる必要性・可能性は ありますか。

\section{敛木 治 :}

チェックをする作業は省けませんが、業務の簡素
化のためには自動化の必要性は十分にあります。 最新型の舶用水晶時計には GPS 受信機との接続 により自動的に時刻整合と地方時管理をさせる機 能を持つものがありますが、船内 LAN に対応す るものではありません。

本研究で明らかになったように NTP の使用は時 刻源と船内 LAN を通じたコンピュータの時刻同 期に有効であり、舶用水晶時計の機能に NTP及び 本研究で提案する LTI 機能を組み込めば、これら を一元化することができることを示しています。

\section{吉村和昭（桐臀横浜大学）:}

船舶においての電波時計の利用の現状を教えて欲 しい。（電波時計は船舶では有用なのか）

\section{㬉木 治 :}

現状において、船舶ではほとんど使用されていま せん。世界中を航行する船舶では、海域ごとに受 信できる放送を利用することになりますが、各国 の時刻コードがまちまちであることや、電波時計 を新たに設置しなければならないこともあり、利 用に汇困難な状況であると言えます。

しかし、本研究の船上実験でも、目標の時刻同期 精度であることが分かりましたので、世界中のあ らゆる海域で受信できる放送体制と、各国の時刻 コードに対応する受信機が登場すれば、船舶での 時刻源として十分有益であると思われます。 